Article

\title{
Does Plant Knowledge within Urban Forests and Parks Directly Influence Visitor Pro-Environmental Behaviors
}

\author{
Beyza Sat Gungor ${ }^{1}$, Jiquan Chen ${ }^{2,3, *}{ }^{(0)}$, Susie R. Wu ${ }^{2}$, Peiling Zhou ${ }^{2}$ and Gabriela Shirkey ${ }^{2}$ \\ 1 Faculty of Architecture and Design, Ozyegin University, Istanbul 34794, Turkey; \\ beyza.gungor@ozyegin.edu.tr \\ 2 Department of Geography, Environment, and Spatial Sciences, Michigan State University, East Lansing, \\ MI 48823, USA; ruqunvi@hotmail.com (S.R.W.); lindaplzhou@gmail.com (P.Z.); shirkeyg@msu.edu (G.S.) \\ 3 Department of Environmental Sciences, University of Toledo, 2801 W. Bancroft St., Toledo, OH 43606, USA \\ * Correspondence: jqchen@msu.edu; Tel.: +1-517-884-1884
}

Received: 14 February 2018; Accepted: 27 March 2018; Published: 28 March 2018

\begin{abstract}
Urban parks and forests provide many services to society and are becoming essential components within urban landscapes worldwide. While substantial research and actions have been taken to understand various ecosystem services of urban forests and parks, significantly less effort has been made on people's perceptions toward the effectiveness of these services. In addressing the above research needs, we conducted a field survey and hypothesized that an individual's knowledge will lead to different pro-environmental behaviors in urban forests and parks. Using the Toledo, Ohio, USA as our study site, we collected 267 interviews from five of the area's most frequented urban parks. A three-way ANOVA and two Partial Least Square Structural Equation Models quantified the causal relationship among demography, plant knowledge, environmental knowledge, and proenvironmental behaviors. We found that: (1) different levels of plant knowledge will have different influences on environmental behaviors; (2) pro-environmental behavioral models can be based on planned behaviors or habitual behaviors; and that (3) gender may not be an influential factor in determining pro-environmental behaviors. Environmental knowledge, especially plant knowledge, plays a key role in fostering pro-environmental behaviors. Therefore, we reason that disseminating plant knowledge education materials will profoundly raise visitors' pro-environmental behaviors.
\end{abstract}

Keywords: pro-environmental behaviors; plant knowledge; partial least square structural equation modeling; urban forests; urban parks; three-way ANOVA

\section{Introduction}

The concept of ecosystem services has been promoted as one of the key foundations in managing natural ecosystems since its creation just decades ago [1,2]. Central to this concept is that natural ecosystems, if managed properly, can produce multiple functions to serve society and people well. The concept is evident even within this special issue's primary focus, "Urban and peril-urban forests (UPFs) can play a pivotal role in supporting the quality of life in our cities". While substantial research and actions have granted an understanding of various ecosystem services and advanced theories, the necessary tools to forecast ecosystem services of various ecosystems across multiple spatiotemporal scales and to demonstrate ecosystem service potential have yet to be thoroughly developed [3,4]. Specifically, people's perceptions toward the effectiveness of these ecosystem services require more attention and focus in the literature. Here, we argue that an individual's knowledge of their surrounding natural environment and behaviors toward it directly relate to their perception of the ecosystem service's effectiveness. Understanding this relationship will contribute to sound, adaptive 
management plans, future policy, and, ultimately, a sustainable maintenance of ecosystems and their services for all society. With the majority of people living in urban areas [5], the need to understand people's perception is ever urgent, especially when promoting global "green" or "smart" cities $[4,6,7]$. In this study, we challenge ourselves with a key question: whether a citizen's pro-environmental behaviors and plant knowledge directly influence their pro-environmental behavior towards urban forests and parks.

Many environmental issues are directly or indirectly associated with human behaviors [8-11], which in turn influence long-term solutions towards these issues [12,13]. It has been hypothesized, for example, that environmental education could have a positive outcome on the pro-environmental behaviors of a society and prevent further irresponsible behavior [13-15]. Similarly, scientific investigations on pro-environmental behaviors are receiving more attention than ever to understand the roles of human behaviors and knowledge towards environmental issues and alternative solutions. For example, strong pro-environmental intentions occur at higher rates among environmentally educated students than among those who are uneducated [14,16-19]. Therefore, environmental education in many nations is becoming a required component in higher education and research programs to promote environmental awareness and action (e.g., Environmental Education Grant offered by United States Environmental Protection Agency).

In the 1980s, environmental education became popular within most educational institutions, leading to new sources of empirical evidence for pro-environmental behavioral scientists. Collected mostly from surveys and interviews with students, the effort to understand education's importance in human behaviors toward environmental issues expanded [16,18,20-22]. These preliminary studies are biased, however, as the students reflect only a part of society, regardless of their future influence. In this study, we included multiple demographic groups to explore society's relationship between pro-environmental knowledge and behavior and hypothesized that plant identification can be effective on the connections between people and nature, which in turn will affect their pro-environmental behaviors.

To test this hypothesis, we surveyed regular park users to explore whether a relationship exists between an individual's plant knowledge and pro-environmental behaviors. Pro-environmental behaviors can be divided into either planned or habitual (e.g., routine) behaviors. The Theory of Planned Behaviors specifies that intention is the direct formative factor for planned behaviors [23]. Following this school of thought, individual pro-environmental intentions can lead to planned pro-environmental behaviors. Habitual behaviors, however, are unconscious behaviors without subjective judgment [24], whereas intention is a reflection of previous behaviors. Habitual proenvironmental behaviors can then lead, modify, or develop pro-environmental intentions and regulate their future pro-environmental behaviors. In addition to people's pro-environmental intentions and behaviors, environmental knowledge can also shape individual pro-environmental behaviors. Although Kollmuss \& Agyeman (2002) argued that a weak association exists between environmental knowledge and pro-environmental behaviors [25], Cottrell et al. (2003) found a significantly tight relationship [26]. Even fewer studies have focused on whether an individual's plant knowledge can affect pro-environmental behaviors. In this study, we further hypothesize that a person's individual knowledge can affect both planned and habitual pro-environmental behaviors. Pro-environmental behaviors can be quantified by tracking the specific actions of an individual, but an alternative is to solicit people's self-reported behaviors (i.e., stated behaviors) with carefully constructed questions in studies where behaviors cannot be observed by the researchers.

We conducted an on-site survey within Toledo, Ohio's top five most-visited urban parks to assess visitor pro-environmental and plant knowledge and ultimately evaluate whether it related to their planned and/or habitual pro-environmental behaviors. By combining both general pro-environmental knowledge (e.g., technologies, environmental issues) and plant knowledge, we collected both institutionally taught and location specific knowledge to explore how the park visitor relates to and understands their natural area's ecosystem services. By disseminating surveys 
on site, we targeted a broad demographic and representation of metro-park visitors. Our overall objective, therefore, explored how people's knowledge on plants and the environment may influence their pro-environmental behaviors by demographic group.

\section{Materials and Methods}

\subsection{Materials}

We chose the top five most visited urban parks in Toledo, Ohio (USA) to conduct our surveys of park visitors: Wildwood Preserve, Toledo Botanical Garden, Ottawa Park, Oak Openings Preserve, and Swan Creek Preserve (https:/ / metroparkstoledo.com/). All urban parks of Toledo (a.k.a. Toledo Metro parks) are open to the public. Toledo's first urban park opened in 1930 with a total of fourteen to follow as the city acquired more land. Over four million visitors enjoy the urban parks each year. These urban parks and forests serve as a venue for natural recreation, daily activities such as jogging and cycling, and environmental education centers. Local plant specimens from the urban park were included in the survey's questionnaire.

\subsection{The Questionnaire \& Design}

We assumed that plant knowledge affects pro-environmental behaviors. Aside from the limited literature discussing plant knowledge, few studies have covered an individual's demographic influence on their pro-environmental behavior. In light of these results, we designed our survey questionnaire to include demographic information, as well as 27 questions partitioned into four categories: plant knowledge, environmental knowledge, pro-environmental intention (future behaviors), and pro-environmental behaviors (Table 1). The primary demographics collected in our survey to evaluate pro-environmental behaviors included education level, age, and gender. Survey participants were also evaluated for their level of knowledge. We assume that the ability to identify plant species is a meaningful indication of a visitor's knowledge about a park and/or forest, although other measures (e.g., scenery, locations, unique landscape features) may be also used as credible indicators. Common tree species found in the urban parks were included in the questionnaire to understand a participant's plant knowledge and capability to identify native plants. Based on the participant's ability to match the species' image with its correct name, we analyzed the relationship between knowledge and self-reported pro-environmental behaviors.

Table 1. The survey questionnaire includes four main categories: plant knowledge (PK), environmental knowledge (EK), pro-environmental intentions (IN); future behaviors (FB), and pro-environmental behaviors (AB). Demographics include gender $(G)$, age (AG), and education (ED).

\begin{tabular}{lcl}
\hline \multicolumn{1}{c}{ Questionnaire } & Acronym & \multicolumn{1}{c}{ Explanations } \\
\hline $\begin{array}{l}\text { Categories Plant } \\
\text { knowledge }\end{array}$ & PK & $\begin{array}{l}\text { Photos of common plants in the Toledo area showing typical } \\
\text { features of the plants including leaves, fruits, and flowers. } \\
\text { Volunteers were asked to match the photos with plant name. }\end{array}$ \\
\hline $\begin{array}{l}\text { Environmental } \\
\text { knowledge }\end{array}$ & EK & $\begin{array}{l}\text { Popular environmental issues facing the local ecosystems and } \\
\text { environmental terminology. }\end{array}$ \\
\hline $\begin{array}{l}\text { Pro-environmental } \\
\text { intention }\end{array}$ & IN (FB) & $\begin{array}{l}\text { Willingness for people to behave in an environmental way in their } \\
\text { daily lives. }\end{array}$ \\
\hline $\begin{array}{l}\text { Pro-environmental } \\
\text { behaviors }\end{array}$ & AB & $\begin{array}{l}\text { Behaviors of participant in environmental protections (e.g., } \\
\text { waste reduction, recycling, energy saving, etc.). }\end{array}$ \\
\hline Demographics & G & Male or female \\
\hline Gender & AG & Adults (>18 years old) \\
\hline Age & ED & $\begin{array}{l}\text { Highest education level achieved: primary/secondary school, high } \\
\text { school, two-year college, four-year college, and graduate studies }\end{array}$ \\
\hline Education & &
\end{tabular}


In this questionnaire, we test two types of knowledge to evaluate its influence the pro-environmental behavior (Table 2): plant knowledge (PK) and environmental knowledge (EK). Knowledge itself is processed by awareness and perception before translating into a behavior. Scientific information, meanwhile, is based on logical reasoning and is indifferent and impassive. The difference between individuals who hold either perception can result in a wide assortment of opinions and behaviors. For example, a scientifically articulated individual will easily comprehend the science behind their environment but demonstrate fewer pro-environmental behaviors, while someone who is less scientifically articulated may be more inclined to exert pro-environmental behaviors due to a higher awareness [16]. We view plant and environmental knowledge as the most fundamental variables that influence the pro-environmental behavior of a visitor. Environmental knowledge represents the understanding of environmental and/or basic sciences, which is more abstract and impersonal than local plant knowledge. However, personal emotion and one's care for the environment are responsible for translating environmental knowledge into action and behavior [27]. To link the visitor's awareness towards their perceived beauty and inspiration by their environment [28], as well as their own emotions and care towards their local environment, our surveys included colorful illustrations of native plant species found throughout the urban park.

Table 2. Mean and standard deviation (STD) of plant knowledge (PK) score and environmental knowledge (EK) score by gender, age (18-39 or $>40$ years old), and education.

\begin{tabular}{|c|c|c|c|c|c|c|c|c|}
\hline \multirow{2}{*}{ Gender } & \multirow{2}{*}{ Age } & \multirow{2}{*}{ Education } & \multicolumn{3}{|c|}{ PK } & \multicolumn{3}{|c|}{ EK } \\
\hline & & & Mean & STD & $\mathbf{N}$ & Mean & STD & $\mathbf{N}$ \\
\hline \multirow{9}{*}{ Female } & \multirow[t]{3}{*}{$40-$} & Low & 6.05 & 2.56 & 38 & 1.50 & 1.18 & 38 \\
\hline & & High & 7.06 & 2.58 & 51 & 2.04 & 1.41 & 51 \\
\hline & & Total & 6.63 & 2.60 & 89 & 1.81 & 1.34 & 89 \\
\hline & \multirow[t]{3}{*}{$40+$} & Low & 4.20 & 2.57 & 10 & 1.70 & 0.95 & 10 \\
\hline & & High & 7.98 & 2.11 & 46 & 2.17 & 1.18 & 46 \\
\hline & & Total & 7.30 & 2.62 & 56 & 2.09 & 1.15 & 56 \\
\hline & \multirow[t]{3}{*}{ Total } & Low & 5.67 & 2.64 & 48 & 1.54 & 1.13 & 48 \\
\hline & & High & 7.49 & 2.40 & 97 & 2.10 & 1.30 & 97 \\
\hline & & Total & 6.89 & 2.62 & 145 & 1.92 & 1.27 & 145 \\
\hline \multirow{9}{*}{ Male } & \multirow[t]{3}{*}{$40-$} & Low & 3.76 & 1.25 & 17 & 2.29 & 1.45 & 17 \\
\hline & & High & 3.73 & 1.37 & 37 & 2.11 & 1.54 & 37 \\
\hline & & Total & 3.74 & 1.32 & 54 & 2.17 & 1.50 & 54 \\
\hline & \multirow{3}{*}{$40+$} & Low & 2.71 & 1.60 & 7 & 0.86 & 0.90 & 7 \\
\hline & & High & 4.58 & 1.82 & 48 & 2.56 & 1.27 & 48 \\
\hline & & Total & 4.35 & 1.89 & 55 & 2.35 & 1.35 & 55 \\
\hline & \multirow[t]{3}{*}{ Total } & Low & 3.46 & 1.41 & 24 & 1.88 & 1.45 & 24 \\
\hline & & High & 4.21 & 1.68 & 85 & 2.36 & 1.40 & 85 \\
\hline & & Total & 4.05 & 1.65 & 109 & 2.26 & 1.42 & 109 \\
\hline \multirow{9}{*}{ Total Male and Female } & \multirow[t]{3}{*}{$40-$} & Low & 5.35 & 2.47 & 55 & 1.75 & 1.31 & 55 \\
\hline & & High & 5.66 & 2.71 & 88 & 2.07 & 1.46 & 88 \\
\hline & & Total & 5.54 & 2.61 & 143 & 1.94 & 1.41 & 143 \\
\hline & \multirow{3}{*}{$40+$} & Low & 3.59 & 2.29 & 17 & 1.35 & 1.00 & 17 \\
\hline & & High & 6.24 & 2.60 & 94 & 2.37 & 1.24 & 94 \\
\hline & & Total & 5.84 & 2.72 & 111 & 2.22 & 1.25 & 111 \\
\hline & \multirow[t]{3}{*}{ Total } & Low & 4.93 & 2.52 & 72 & 1.65 & 1.25 & 72 \\
\hline & & High & 5.96 & 2.66 & 182 & 2.23 & 1.35 & 182 \\
\hline & & Total & 5.67 & 2.66 & 254 & 2.06 & 1.35 & 254 \\
\hline
\end{tabular}

We hypothesized that the participant would be more likely to engage in pro-environmental behavior and intentions if they had higher levels of plant identification and environmental knowledge, which we extracted from the survey score. Plant knowledge was determined through nine quizzes (Supplement Materials, Appendix A: Q1-Q9). Tree species common in the Toledo urban parks and forests were featured in pictures for participants to match with a list of names, including: maple 
(Acer sp.), spruce (Pica sp.), sycamore (Plotinus sp.), oak (Quercus sp.), cottonwood (Populous sp.), dogwood (Cronus sp.), honeysuckle (Locker sp.), basswood (Talia sp.), ash (Fraxion's sp.), mulberry (Murus sp.), and pine (Pinups sp.) (Supplement Materials, Appendix B). A participant's final score indicates their awareness of plants. Environmental knowledge was based on the participant's score when answering five environmental questions, which included major environmental issues that do not require expert knowledge (Supplement Q15, Q16, Q19, Q20, Q22) such as global warming, carbon emissions, green technology, etc.

Self-reported pro-environmental intentions and behaviors including energy saving and recycling activities in everyday life evaluated the causal relationship between intentions to behaviors [23,29]. The pro-environmental behaviors were measured by frequency (Supplement Q14A-Q14J), which was divided into three classes: never, sometimes, and always. Intention was measured by the frequency of the corresponding behaviors, which consisted of four categories: never, sometimes, often, and always (Supplement Appendix A Q24A-Q24H).

\subsection{The Surveys}

We conducted our surveys during the summer of 2014 using in-person convenience sampling. The population of the Greater Toledo Area (i.e., Lucas County) was 432,488 in 2016 according U.S. Census Bureau (https:/ / www.census.gov/quickfacts/fact/table/lucascountyohio/PST045216, accessed on 7 March 2017), with approximately 278,000 residents in the city of Toledo. This assures a $90 \%$ confidence level and a margin error of 5\%. We collected 267 completed surveys from adults (>18 years old). The amount of the questionnaires determined at the study design was chosen so as to sample $\sim 1 \%$ of the population (i.e., 270). Our survey sites were located in populated and diversified districts in Toledo. We found that most visitors included retirees and homemakers during working hours (9:00 a.m.-5:00 p.m.), while professionals visited the parks and urban forests after 5:00 p.m. To ensure sample diversity, we continued surveying during both periods of time and within different age, gender, and education groups.

\subsection{Analysis of Variance (ANOVA)}

Age (AG) divides the surveys into two groups: 18-39 and >40 years old (Table 2). Education (ED) divides the surveys into a low or high group, where the low group includes those with primary school, secondary school, and a two-year college education; the high education group includes those with four-year college degrees and graduate school education (Table 2). A three-way analysis of variance (ANOVA) was used to test the effects of different factors (age, gender, and education) and their interactions with plant knowledge (PK) and environmental knowledge (EK) in a general linear model:

$$
Y=\mu+\alpha+\beta+\gamma+\alpha \times \beta+\beta \times \gamma+\alpha \times \gamma+\alpha \times \beta \times \gamma+\text { error }
$$

where $\mu$ is the predicted mean, and $\alpha, \beta, \gamma$ represent age, gender, and education, respectively.

\subsection{Structural Equation Modeling (SEM)}

Our SEM models are comprised of two observed variables (PK and EK) and two latent variables (IN/FB and AB, Table 1). Two models developed the SEM. The first SEM (planned behavioral model) hypothesized that the pro-environmental behaviors (AB) of the visitors are planned behaviors, where AB is caused by IN (Figure 1a). The second SEM model (habitual behavioral model) hypothesized that the behaviors were unplanned behaviors, which can influence FB. Pro-environmental intention (IN) is indicated by FB in the habitual behavioral model. We also tested if age (AG), education (ED), and gender $(G)$ would influence pro-environmental behaviors. These models explain how pro-environmental behaviors may form. We focused on the interactions among the behavioral factors, as well as their statistical relationships. 
(a) Intention caused actual behaviors

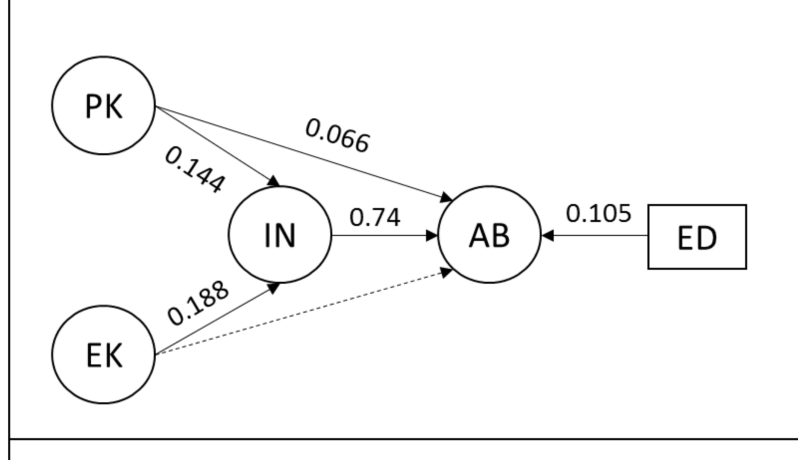

(b) Actual behaviors caused future behaviors

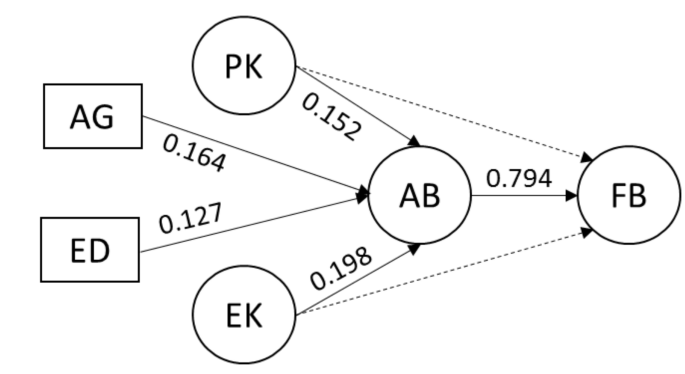

Figure 1. Path diagram of structural equation model (SEM) of pro-environmental behaviors based on two scenarios. The solid lines indicate significant relationships, while dash lines indicate non-significant relationships between plant knowledge (PK), environmental knowledge (EK), pro-environmental intentions (IN; FB), and pro-environmental behaviors (AB). Demographics include gender (G), age (AG), and education (ED).

Partial least square structural equation modeling (PLS-SEM) is applied as our primary statistical tool for achieving the study objective because there is little priori knowledge or theoretical base on the causal relationship [30]. Compared with confirmatory, covariance-based SEM (CB-SEM), PLS-SEM is the preferred method when the research object is for theory development, particularly when there is little priori knowledge on structural model relationships and the emphasis is more on exploration than confirmation [31]. Also, PLS-SEM works effectively with small sample sizes, especially when formatively measured constructs (i.e., latent variables) are constructed as a component of the SEM [31]. Suites of hypotheses were tested through SEMs (Table 3).

Table 3. Supported and unsupported relationships of the two structural equation models (SEM) by hypotheses testing based on bootstrapping with individual changes algorithm. Model A: planned behavioral model; Model B: habitual behavioral model; CI: confident interval; b: path coefficient; A: accepted hypothesis; R: rejected hypothesis.

\begin{tabular}{cccc}
\hline Model A & b & CI (Lower) & CI (Upper) \\
\hline $\mathrm{PK} \rightarrow \mathrm{AB}(\mathrm{A})$ & 0.066 & 0.003 & 0.185 \\
$\mathrm{PK} \rightarrow \mathrm{IN} \mathrm{(A)}$ & 0.144 & 0.005 & 0.290 \\
$\mathrm{EK} \rightarrow \mathrm{AB}(\mathrm{R})$ & 0.043 & 0.000 & 0.143 \\
$\mathrm{EK} \rightarrow \mathrm{IN}(\mathrm{A})$ & 0.188 & 0.011 & 0.352 \\
$\mathrm{IN} \rightarrow \mathrm{AB}(\mathrm{A})$ & 0.740 & 0.541 & 0.837 \\
$\mathrm{G} \rightarrow \mathrm{AB}(\mathrm{R})$ & 0.008 & 0.000 & 0.030 \\
$\mathrm{AG} \rightarrow \mathrm{AB}(\mathrm{R})$ & 0.039 & 0.000 & 0.138 \\
$\mathrm{ED} \rightarrow \mathrm{AB}(\mathrm{A})$ & 0.105 & 0.009 & 0.222 \\
\hline
\end{tabular}


Table 3. Cont.

\begin{tabular}{cccc}
\hline Model B & & & \\
\hline $\mathrm{PK} \rightarrow \mathrm{AB}(\mathrm{A})$ & 0.152 & 0.010 & 0.319 \\
$\mathrm{PK} \rightarrow \mathrm{FB}(\mathrm{R})$ & -0.035 & -0.114 & 0.000 \\
$\mathrm{EK} \rightarrow \mathrm{AB}(\mathrm{A})$ & 0.198 & 0.016 & 0.367 \\
$\mathrm{EK} \rightarrow \mathrm{FB}(\mathrm{R})$ & 0.004 & 0.000 & 0.011 \\
$\mathrm{AB} \rightarrow \mathrm{FB}(\mathrm{A})$ & 0.794 & 0.657 & 0.842 \\
$\mathrm{G} \rightarrow \mathrm{AB}(\mathrm{R})$ & 0.051 & 0.000 & 0.160 \\
$\mathrm{AG} \rightarrow \mathrm{AB}(\mathrm{A})$ & 0.164 & 0.006 & 0.318 \\
$\mathrm{ED} \rightarrow \mathrm{AB}(\mathrm{A})$ & 0.127 & 0.008 & 0.308 \\
\hline
\end{tabular}

Formative measurement was applied to measure the two latent variables (Figure 2) so that internally consistent reliability checks and indicator reliability checks would not be required [32] and so that criteria such as Cronbach's alpha, composite reliability, AVE, and cross-loadings would not be needed. We checked the inner and outer VIF for collinearity. They all met the rule of thumb with a threshold of VIF $<5$.

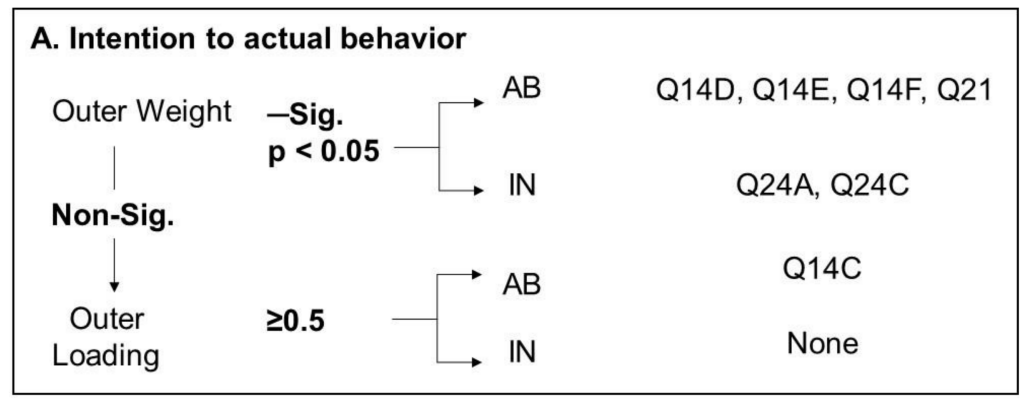

B. Actual behavior to future behavior

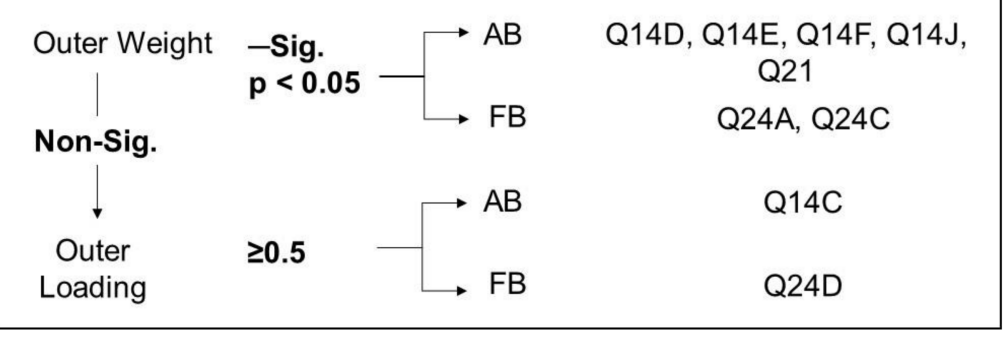

Figure 2. Decision making process for eliminating formative items of each construct and the results of the two SEM models: (Model A) planned behavioral model and (Model B) the habitual behavioral model.

Smart PLS 3.0 constructed our PLS-SEM, which does not assume normally distributed data but rather relies on a nonparametric bootstrap procedure [30,32-34]. Our selection criteria were based on the Decision-Making Process for Keeping or Deleting Formative indicators proposed (Figure 1) [32]. In this process, the significance of outer weight for the model is tested first. When the outer weight is significant with $p<0.05$, the formative items can be retained. When the outer weight is not significant, the formative indicators' outer loading requires further analysis. If the outer loading is $>0.5$, the formative items can still be retained. Otherwise, the items must be removed from the corresponding aspects. Bootstrapping with individual sign change resulted in the deletion of several items used for aspects of actual behaviors and future behaviors (intention). Bootstrapping is a resampling process in PLS-SEM for testing the statistical significance. The common algorithms used for bootstrapping have no sign change or individual sign change [32]. By bootstrapping with individual changes, we tested this series of specific hypotheses (Table 3). 


\section{Results}

\subsection{Survey Results}

Completed surveys included 145 females and 109 males with complete education, age, and level of education. For the highest level of education in females, 1\% completed primary school, 32\% high school, 22\% had a two-year college degree, 19\% had a four-year college degree, and $26 \%$ had a graduate degree (Figure 3a). Highest levels of education in the male population were $22 \%$ high school, $24 \%$ a two-year college degree, $28 \%$ had a four-year college degree, and $27 \%$ had a graduate degree (Figure 3b).

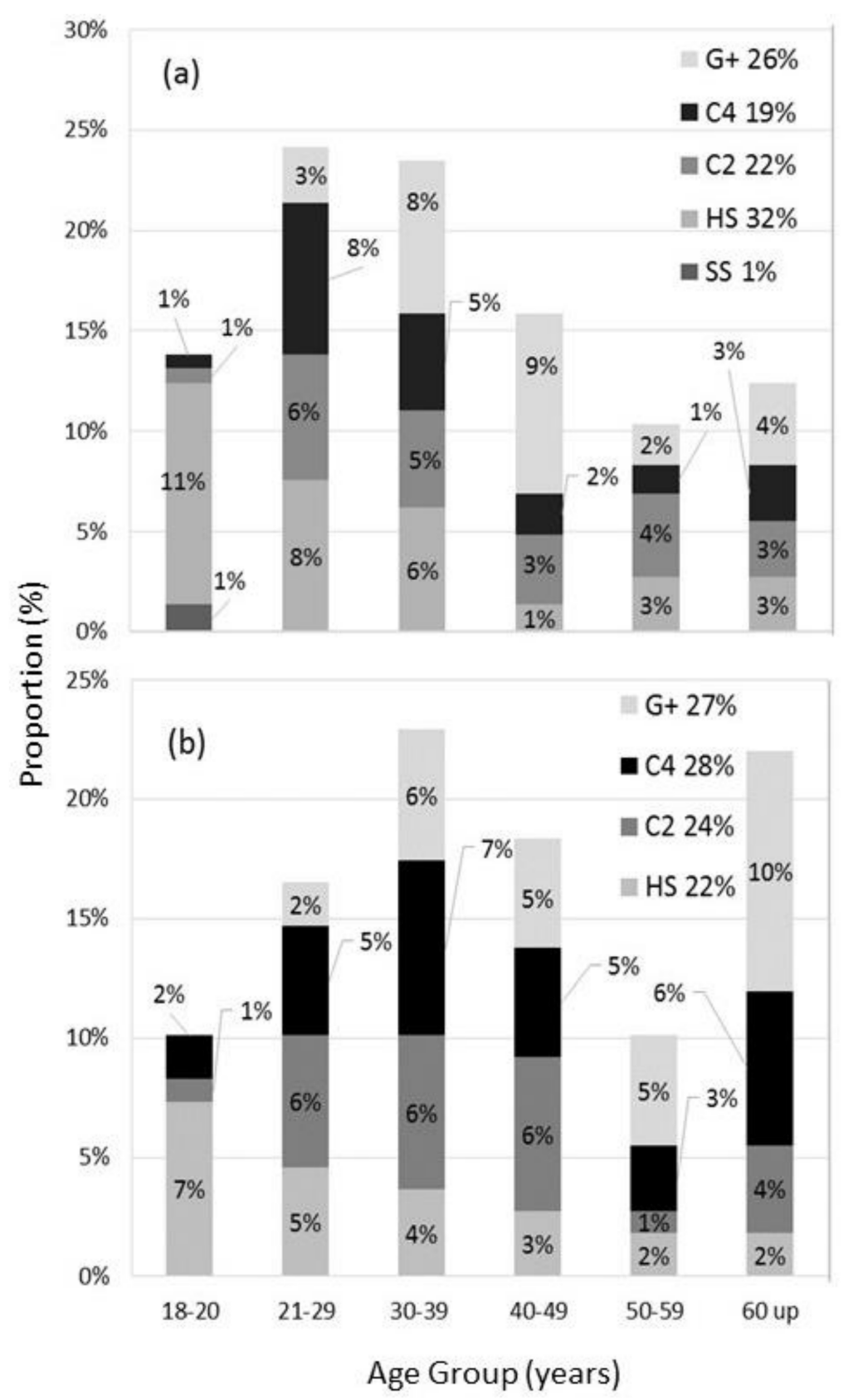

Figure 3. Composition of surveyed visitors (population \%) for female (a) and male (b) by age and education. SS: Secondary school, HS: High school, C2: two-year college, C4: four-year college, G+: Graduate education. 


\subsection{ANOVA Results}

The ANOVA on plant knowledge (PK) indicated significant effects from gender $(P=0.00)$, education $(P=0.00)$, education $x$ gender $(P=0.03)$, and education $x$ age $(P=0.00)$ (Table 4 , Figure $4 a)$. For environmental knowledge (EK), we found significant effects from education $(P=0.00)$, age $x$ education $(P=0.03)$, and the three-way interaction between education, age, and gender $(P=0.02)$ (Table 4, Figure $4 \mathrm{~b}$ ).

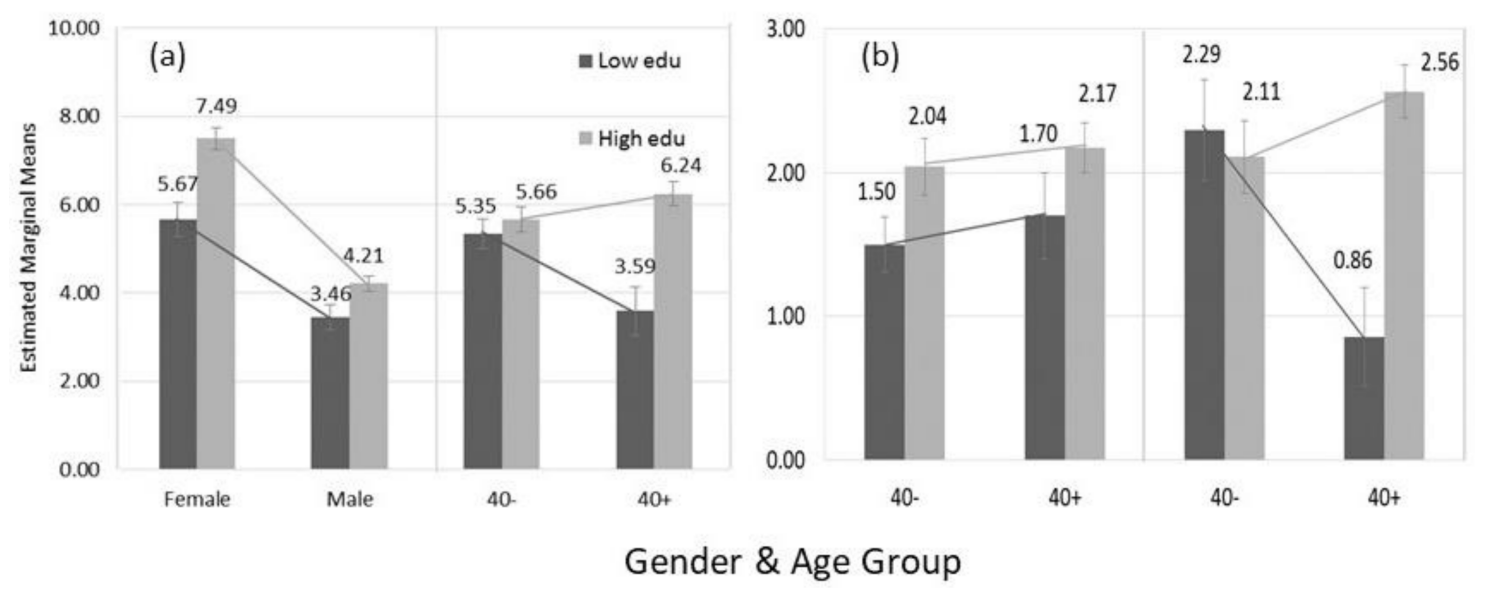

Figure 4. Contrasts of estimated marginal means of (a) plant knowledge; (b) environmental knowledge among different demographic groups. Only means with significant differences are shown.

Table 4. Statistical results of ANOVA (Equation (1)) on the effects of gender (G), age (AG), and education (ED) on plant knowledge (PK) and environmental knowledge (EK).

\begin{tabular}{ccccccccccc}
\hline \multirow{2}{*}{ Source } & \multicolumn{9}{c}{ PK } & \multicolumn{7}{c}{ EK } \\
\cline { 2 - 11 } & SSE & de & MSE & F & P & SSE & de & MSE & F & P \\
\hline G & 264.14 & 1 & 264.14 & 59.14 & 0.00 & 0.40 & 1 & 0.40 & 0.23 & 0.63 \\
AG & 3.06 & 1 & 3.06 & 0.69 & 0.41 & 1.01 & 1 & 1.01 & 0.59 & 0.44 \\
ED & 105.00 & 1 & 105.00 & 23.51 & 0.00 & 15.37 & 1 & 15.37 & 8.96 & 0.00 \\
G $\times$ AG & 1.30 & 1 & 1.30 & 0.29 & 0.59 & 4.16 & 1 & 4.16 & 2.43 & 0.12 \\
G $\times$ ED & 20.86 & 1 & 20.86 & 4.67 & 0.03 & 0.61 & 1 & 0.61 & 0.36 & 0.55 \\
AG $\times$ ED & 52.41 & 1 & 52.41 & 11.73 & 0.00 & 7.99 & 1 & 7.99 & 4.66 & 0.03 \\
G $\times$ AG $\times$ ED & 1.81 & 1 & 1.81 & 0.40 & 0.53 & 9.18 & 1 & 9.18 & 5.35 & 0.02 \\
Error & 1098.75 & 246 & 4.47 & & & 421.90 & 246 & 1.72 & & \\
\hline
\end{tabular}

Gender relationships with PK indicated that, on average, females (6.89) had more plant identification knowledge than males (4.05); and that education's relationship with PK suggested that low-educated visitors (4.93) had less plant identification knowledge than highly-educated visitors (5.96) (Table 2). The significant, interactive effects from gender and education further indicated that, on average, plant identification knowledge for both low-educated females (5.67) and males (3.46) and high-educated females (7.49) and males (4.21) varied significantly by gender.

The significant interaction between age and education indicated that, on average, people of 40years age (5.35) were less educated and had more plant identification knowledge than those with 40+ years of age (3.59). However, the highly-educated people of the 40+ year age group (6.24) had more plant identification knowledge than people of the 40- age year group (5.66) (Tables 2 and 4, Figure 4).

This significant effect from education on environmental knowledge appeared to be coupled with insignificant, independent effects from gender and age (Table 3). The environmental knowledge of a low-educated group (1.65) was less than that of the highly-educated group (2.23) (Table 2). A significant, interactive effect from age and education that was not consistent across the two gender groups was found. This caused a significant three-way interaction between gender, age, and education. Females of 
$40-$ years age (low $=1.50$, high $=2.04$ by education) had less environmental knowledge than those at $40+$ years age (low $=1.70$, high $=2.17)$. Low-educated males $(2.29)$ had more environmental knowledge than highly educated males (2.11) when they were 40- years of age. Additionally, low-educated males of 40 - years of age (2.29) had more environmental knowledge than those of $40+$ years age (0.86). However, this was the opposite case for highly educated males $(40-$ years $=2.11 ; 40+$ years $=2.56)$ (Tables 2 and 4, Figure 4b).

\subsection{PLS-SEM Results}

Formative factors of pro-environmental intention and behaviors were selected by the PLS-SEM (Figure 2). In model A, the remaining items for AB were comprised of five questions about reducing waste, reusing useful waste, recycling waste, reducing cook-related pollution, and waste sorting (supplement Q14 C, D, E, F, and Q21), while the remaining items for IN were formed by two questions on reusing useful waste and recycling waste (supplement Q24 A, C). In model B, the remaining items for AB included Q14C, D, E, F, J, and Q21, where Q14 and J were about minimizing detergent use, while the remaining items for FB included: Q24A, C, D, and Q24, where D was about the purchase of environmental household products (Figure 2).

Significant casual relationships were found between IN and AB, and between AB and FB (Table 3, Figure 1). The PLS-SEM tested the hypotheses based on the confidence interval. The significant influence was verified if the confidence interval did not cover 0 . In model $A$, we proved that IN can significantly influence AB (CV [0.541, 0.837]) and that PK can significantly influence both AB (CV $[0.003,0.185])$ and IN (CV [0.005, 0.290]), while EK did not influence AB (CV [0, 0.143]), only IN (CV $[0.011,0.352])$. However, ED was the only demographic variable which could influence AB significantly (CV [0.009, 0.222]).

In model $B$, we found a significant effect from PK on $A B(C V[0.010,0.319])$ and a significant effect from EK on AB (CV [0.016, 0.367]). Both EK (CV [-0.114, 0]) and PK (CV [0, 0.011]) did not influence FB significantly. A significant effect was found from AB to FB (CV [0.657, 0.842]). Both AG (CV [0.006, 0.318]) and ED (CV [0.008, 0.308]) significantly influenced actual behaviors in model B (Table 3, Figure 1b).

\section{Discussion}

\subsection{The Influences of Demography on Knowledge}

Through our ANOVAs, females (6.89) show more PK than males (4.05) (Figure 4a, Table 2), which indicates that females exhibit more knowledge than males in recognizing plants. A possible explanation is that women may have more access to plant identification knowledge than men; however, there is much discussion regarding historical gender roles in gardening and botany [35,36]. We also found that education was a major factor responsible for the difference between PK and EK among the visitors. However, there was an exception-low educated females (5.67) had more PK than highly educated males (4.21). From this study, it seemed that females are more knowledgeable on PK than males, regardless of the education background. Low educated males 40- years of age (2.29) knew more EK than those of the $40+$ years of age group (0.86). Additionally, all visitors $40-$ years of age (5.35) knew more PK than visitors 40+ years of age (3.59), regardless of gender. This could be a result of progress in the education system, as current students always gain more knowledge than their predecessors [14,18]. However, highly educated visitors were an exception, possibly because education enhances people's ability in self-education. This might also be the reason that groups $40+$ years of age $(6.24,2.37)$ were highly educated and had more knowledge in both EK and PK than those $40-$ years of age $(5.54,2.07)$ (Figure 4 , Table 2$)$. 


\subsection{The Influences from Knowledge on Actual Behaviors}

When creating SEM models, our hypotheses considered two possible types of pro-environmental behaviors: planned behaviors and habitual behaviors (Figure 1, Table 3). Harland et al. (1999) explained that pro-environmental behaviors are planned behaviors [37]. We explored pro-environmental behaviors as habitual behaviors in this study, as there is very little research on this topic. Both models found significant relationships between $\mathrm{AB}$ and IN/FB (i.e., IN is intention in the planned behavioral model [Model A], FB is future behaviors in the habitual model [Model B]). In the planned behavioral model, pro-environmental intention is based on subjective judgment and decision-making, which is constructed according to an individual's ethics on non-profitable and environmentally friendly behaviors. In the habitual behavioral model, pro-environmental behaviors will occur when the pro-environmental behavior is repeated enough to form a habit [24]. Additionally, the behaviors conducted without consideration or planning can lead to a reflection, which in turn will form an intention that can indicate future behavior. Therefore, we recognized the intention as a future behavior in the habitual behavioral model. The two behavioral models can then be used for analyzing pro-environmental behaviors.

The casual relationships between $\mathrm{AB}$ and IN/FB in the planned behavioral model and the habitual behavioral model are statistically inversed. The causal inference by PLS-SEM supported both hypotheses (IN $\rightarrow \mathrm{AB}[0.541,0.837], \mathrm{AB} \rightarrow \mathrm{FB}[0.657,0.842])$. Hence, it is possible that both behavioral models exist together. The cause-effect connection between intention and actual behaviors can be seen as either one-directional or a loop. Because PLS-SEM could only test one-directional causal action, we did not test the hypothesis on loops. Further study is necessary to answer this question.

Two types of knowledge have different influences on pro-environmental behavior (Figure 1, Table 3), including EK and PK. Environmental knowledge in our questionnaire covered many popular issues such as climate change and the depletion of natural resources. These issues could directly motivate and develop an intuition in people to value and protect the environment. Plant knowledge in our survey, on the other hand, relates less to current issues than EK and relates more to the aesthetics and science of nature. This knowledge attracts people to learn and, consequently, it can motivate people to value and protect it. For most cases, EK directly relates to human survival, whereas PK is closely related to the natural environment. Therefore, PK is perceived as not as useful as EK. For a market-driven society, knowledge is a product with certain utility [38]. Therefore, EK is seen as more valuable than PK because the economy, investment, health, jobs, and other aspects of life rely directly on EK rather than PK.

The planned behavioral model (A) provided evidence that both EK and PK significantly influence IN (EK $\rightarrow$ IN [0.011, 0.352], PK $\rightarrow$ IN [0.005, 0.290]). Interestingly, only PK can significantly influence $\mathrm{AB}(\mathrm{EK} \rightarrow \mathrm{AB}[0,0.143], \mathrm{PK} \rightarrow \mathrm{AB}[0.003,0.185])$. This implies that $\mathrm{EK}$ and $\mathrm{PK}$ can motivate pro-environmental intention, but only $\mathrm{PK}$ can motivate $\mathrm{AB}$ to protect the environment. In other words, PK is more important than EK to motivate pro-environmental behaviors, although the utility and monetary value of EK is more perceptible (Figure 2).

The habitual behavioral model (B) provided evidence that both EK and PK can significantly influence $\mathrm{AB}$ ( $\mathrm{EK} \rightarrow \mathrm{AB}[0.016,0.367], \mathrm{PK} \rightarrow \mathrm{AB}[0.010,0.319])$. However, neither of them can significantly influence FB (EK $\rightarrow$ FB $[0,0.011]$, PK $\rightarrow$ FB $[-0.114,0]$ ). In a habitual behavior, reflection is based on personality and ethical values. People judge their habits as good or bad based on their morality, social norms, and many other psychological factors. Therefore, this reflection is not directly determined by knowledge. The result is consistent with our finding that FB (i.e., the reflection of actual behavior) is not significantly influenced by knowledge, although knowledge could influence $\mathrm{AB}$ (Figure 2).

\subsection{The Influence from Education, Gender and Age on Actual Behaviors}

Our research includes three demographic variables: age, gender, and education. The result of ANOVA shows how these three factors cause the difference in the PK and EK for visitors. PLS-SEM 
also tested how the three factors influence the $\mathrm{AB}$. In the planned behavioral model, only ED has a significant influence on $\mathrm{AB}(0.009,0.222)$. Education as a major effect causes the difference of both EK and PK among visitors, and is also shown to be able to influence the AB. It implies that ED is an important factor to determine the pro-environmental behaviors. Education could improve both the knowledge and behaviors of people. In the habitual behavioral model, ED $(0.008,0.308)$ and AG $(0.006$, 0.318 ) can significantly and positively influence $A B$. Age is a major effect that can differentiate a population in many behavioral analyses. Different age groups will have different habitual patterns or characteristics.

While not in the planned behavioral model, the habitual behavioral model demonstrates that older people tend to be more pro-environmental than younger people ( $\mathrm{AG} \rightarrow \mathrm{AB}[0.006,0.318]$ ). The reason for this may come from two perspectives: (1) the fast growth of the consumer market attracts people to consume more than before; and (2) the culture of younger generations values convenience more than older generations. Unfortunately, in the second perspective, convenience-based lifestyles cause more environmental issues (e.g., disposable cups, plastic bags, and unsorted waste).

In sum, our PLS-SEM indicates that gender is not a factor that determines AB in either model. The results of both ANOVA and PLS-SEM indicate that education is an important factor, and that sometimes age can influence both knowledge and behaviors.

\subsection{Uncertainities and Limitations}

Our exploratory analysis with PLS-SEM estimation provided two plausible and informative models. However, the models require more experimental data and further development than what was available. Our data was inherently less robust than CB-SEM when testing the hypothesized model with high confidence because the causal inference was not based on well-developed theories. Before confirming this pro-environmental behavioral model, more surveys need to be developed. Nevertheless, the results are valuable and can serve as a scientific reference for further study. There may be collinearities among knowledge and the other social variables, but the test of inner and outer VIF for collinearity met the cut-off value with a threshold VIF $<5$ [31].

The two behavioral models can both be feasible explanations. There is rich literature on the applications of the Theory of Planned Behavior to explain environmental behaviors [37,39]. However, there are very few studies explaining environmental behaviors as habitual behaviors [40]. In fact, habitual behaviors guide our daily life activities, which means there is little consideration before an individual behaves pro-environmentally. More critically, our results on "behaviors" are based on visitors' self-reported responses to the survey questions. Our questionnaire is designed to measure the relationships between plant/environmental knowledge and pro-environmental behavior that is self-reported instead of observed behavior. Therefore, the results are indications of actual behaviors; they do not directly indicate the potential casual relationships regardless of the high correlations (Tables 3 and 4; Figure 1). This has been a common problem in behavioral studies [41], due to the difficulties in measuring actual (i.e., observed) behavior. More research is needed to extract accurate causality between people's knowledge on plants and the environment and their actual pro-environmental behaviors. Long-term experiments that directly measure people's behaviors are suggested. Clearly, understanding the mechanisms between planned and habitual pro-environmental behaviors needs further research.

Other limitations of this study include exclusions of other relevant measures of the visitors that might also be critical in influencing their environmental knowledge and pro-environmental behaviors, such as income, living conditions [42], transportation, and walkability [43]. Due to the limitation of data and the small sample size, these factors are not considered in our models but are critical for future endeavors.

\section{Conclusions}

The two behavioral models provided insight and an understanding of daily pro-environmental behaviors, which may be a mix of both plans and habits. Through testing our hypotheses, we found that: 
(1) different knowledge will have different influences on behaviors; (2) pro-environmental behavioral models are useful to study both planned behaviors and habitual behaviors; and that (3) gender may not be an influential factor in determining pro-environmental behaviors. Our current pro-environmental behaviors are a function of education, gender, age, and knowledge, which can be feasible input factors for more psychological and socioeconomic studies in the future. Both models proved that environmental and plant identification knowledge play key roles in fostering pro-environmental behaviors. Similarly, a survey study conducted in Portland, Oregon, USA, revealed a close relation between plant identification and attention to environmental issues [44]. More so, a basic understanding of plants can be even more important than environmental scientific knowledge when influencing planned pro-environmental behaviors; and education levels determine our daily pro-environmental behaviors. As for age, older generations are more environmentally knowledgeable than younger generations when pro-environmental behaviors are already habits. This study will help urban planners develop practical botanical garden strategies and educational material focused on plant identification knowledge to develop their visitors' pro-environmental behaviors.

Supplementary Materials: Materials are available in the online version of the paper. Appendix A: Survey questions for plant identification and green space use; Appendix B: Survey questions for environmental knowledge. The data and questionnaire are available for download and other use, please email Jiquan Chen, corresponding author, at jqchen@msu.edu with questions.

Acknowledgments: The authors are grateful to the University of Toledo for providing the support for B. Gungor for her summer scholarship in 2014. This study is also partially supported by the Sustainable Energy Pathways (CHE) Program (\#1230246) of the US National Science Foundation (NSF). The Adult Research Informed Consent document has been reviewed and approved by the University of Toledo Social, Behavioral and Educational IRB.

Author Contributions: J.C. and B.S.G. designed the study and conducted the field surveys; S.R.W. performed ANOVA and S.E.M.; all authors contributed to data analysis, discussion on the results, and manuscript development.

Conflicts of Interest: The authors declare that they have no competing interests.

\section{Appendix A. Plant Identification and Green Space Use. Please Circle the Correct Response}

- Survey of Relations between Plant Identification and Environmental Protection ConsciousnessUniversity of Toledo

- You are invited to participate in a study that is designed to reveal the relationship between plant identification ability and environmental protection behavior. In this survey, you will be asked to answer several questions regarding plant identification, environmental protection knowledge, and green space use frequency and purpose.

- Participation in this study is voluntary. There is no harm associated with not answering the questions.

- There are no personal questions in the survey; and in any case, all data collected as part of this study will be confidential.

- $\quad$ Please check this box if you are older than 18

Q1-Which one of the tree species is maple tree?

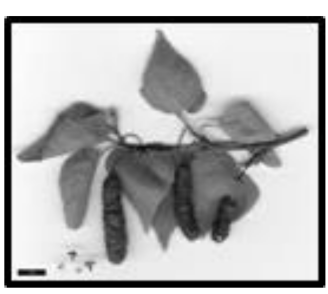

a

(1)

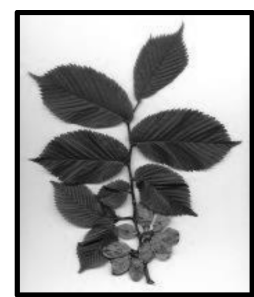

b

(2)
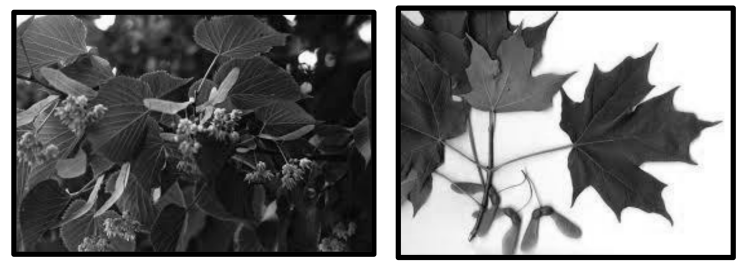

d

(3) 
Q2-Which one of the tree species is spruce tree?

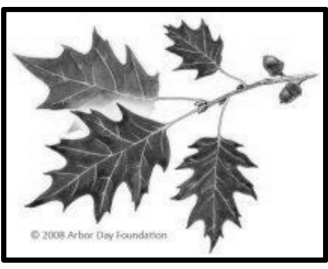

(1)

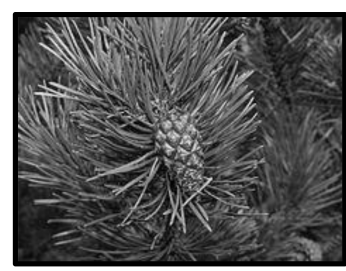

b

(2)

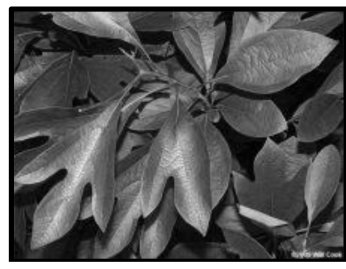

(3)

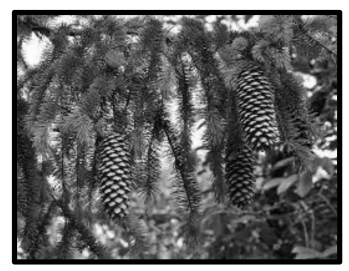

d

(4)

Q3-Which one of the tree species is sycamore tree?

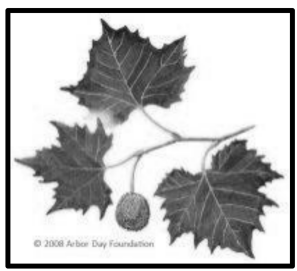

(1)

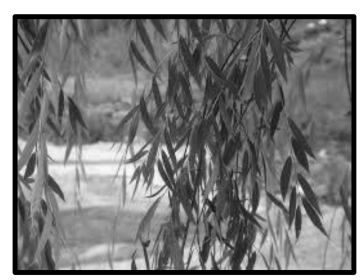

b

(2)

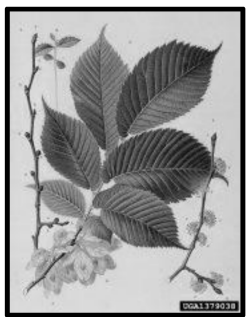

(3)

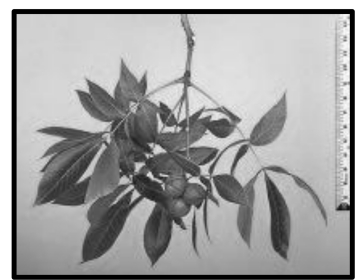

d

(4)

Q4-Which one of the tree species is oak tree?

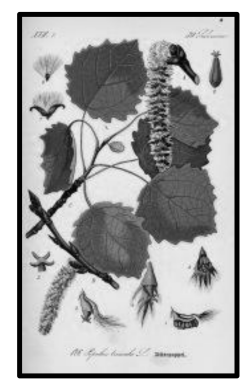

a

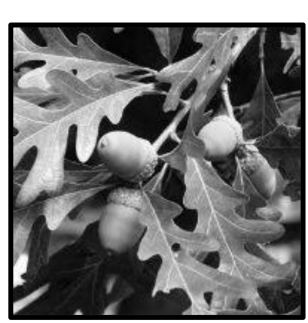

b

(2)

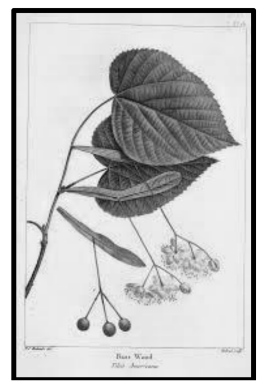

(3)

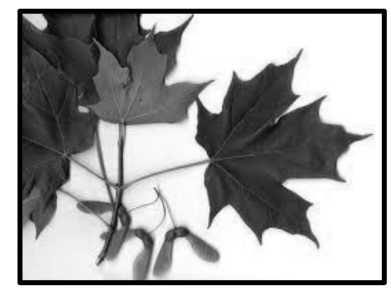

d

(4)

Q5-Which one of the tree species is cottonwood tree?
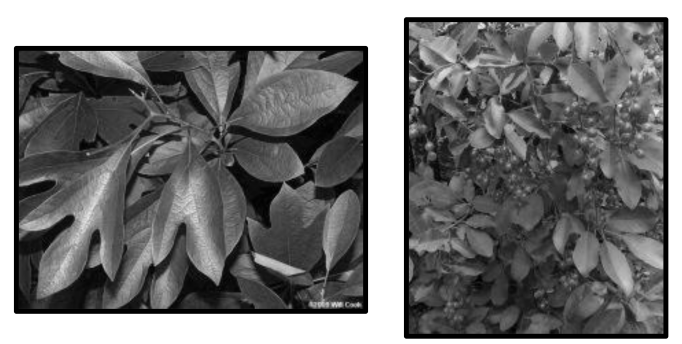

a

(1) b

(2)

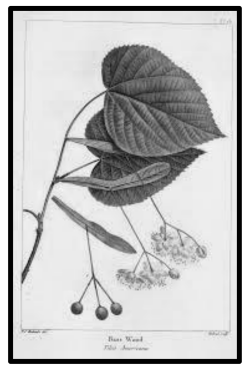

(3)

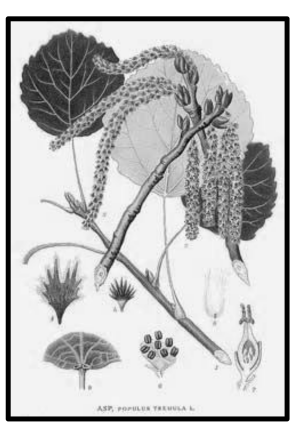

d

(4) 
Q6-Which one of the bush species is dogwood?

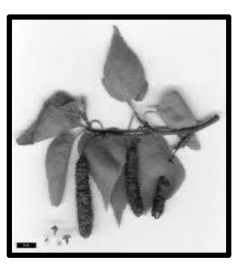

(1)

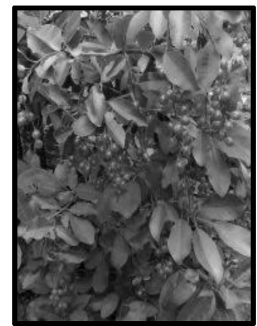

b

(2)

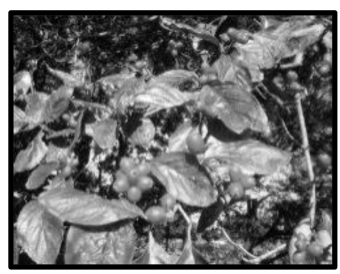

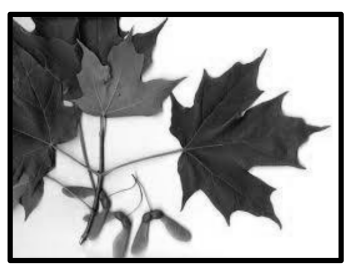

d

(4)

Q7-Which one of the bush species is honeysuckle?

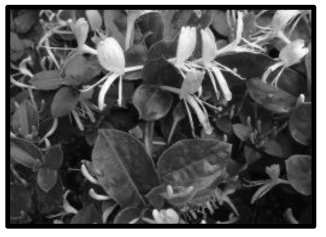

(1)

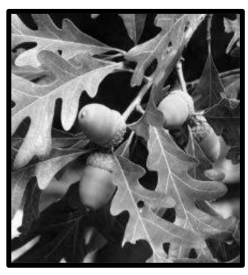

(2)

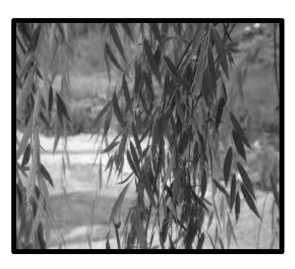

(3)

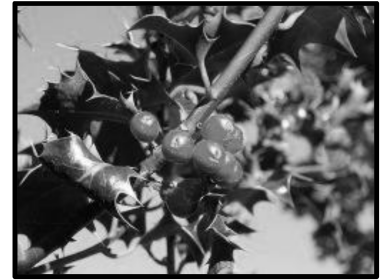

d

(4)

Q8-Which one of the tree species is a basswood?

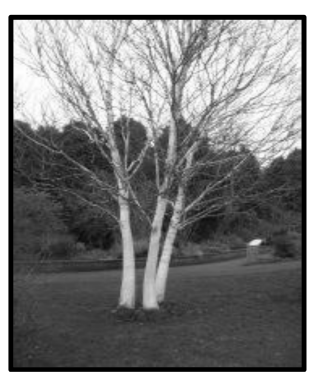

(1)

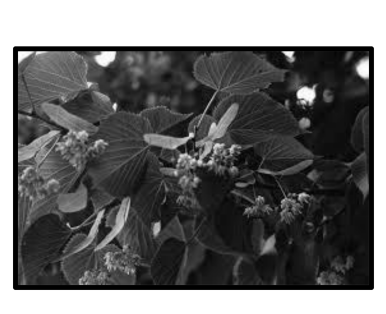

b

(2)

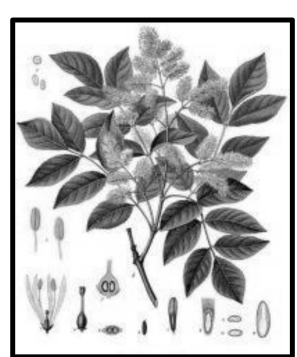

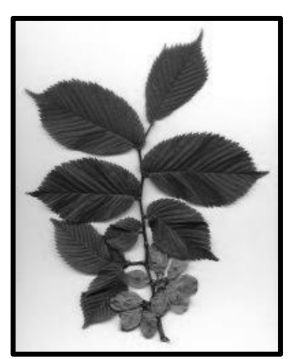

d

(4)

Q9-Can you match the plant photos with plant names?
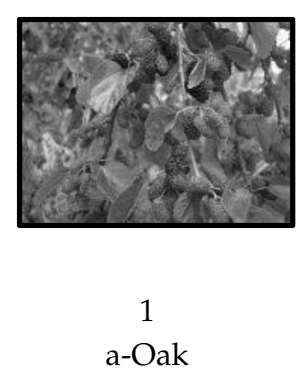
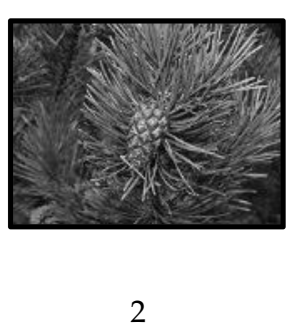

b-Ash

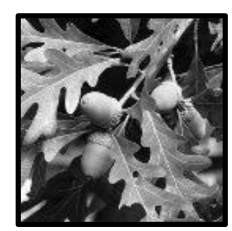

c-Mulberry

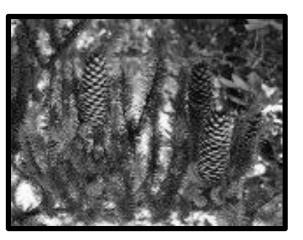

4
d-Spruce

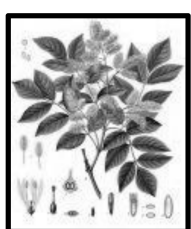

5

e-Pine

Note: (1-5) Every correct answer is worth of 1 point; there are 5 matches; so 5 correct answers equals 5 points. 
Q10-How often do you visit the park?

\begin{tabular}{|c|c|c|c|c|c|c|c|c|}
\hline & & Q10a Summer & & Q10b Fall & & Q10c Winter & & Q10d Spring \\
\hline \multirow{2}{*}{ Week days } & $\checkmark$ & Twice a week (2) & $\checkmark$ & Twice a week (2) & $\checkmark$ & Twice a week (2) & $\checkmark$ & Twice a week (2) \\
\hline & $\checkmark$ & None (4) & $\checkmark$ & None (4) & $\checkmark$ & None (4) & $\checkmark$ & None (4) \\
\hline \multirow{4}{*}{ Weekend } & $\checkmark$ & Only Saturdays (1) & $\checkmark$ & Only Saturdays (1) & $\checkmark$ & Only Saturdays (1) & $\checkmark$ & Only Saturdays (1) \\
\hline & $\checkmark$ & Only Sundays (2) & $\checkmark$ & Only Sundays (2) & $\checkmark$ & Only Sundays (2) & $\checkmark$ & Only Sundays (2) \\
\hline & $\checkmark$ & $\begin{array}{l}\text { Three times in a } \\
\text { month (3) }\end{array}$ & $\checkmark$ & $\begin{array}{l}\text { Three times in a } \\
\text { month (3) }\end{array}$ & $\checkmark$ & $\begin{array}{l}\text { Three times in a } \\
\text { month (3) }\end{array}$ & $\checkmark$ & $\begin{array}{l}\text { Three times in a } \\
\text { month (3) }\end{array}$ \\
\hline & $\checkmark$ & Once in a month (4) & $\checkmark$ & Once in a month (4) & $\checkmark$ & Once in a month (4) & $\checkmark$ & Once in a month (4) \\
\hline
\end{tabular}

Q11-How much time do you spend in the park?

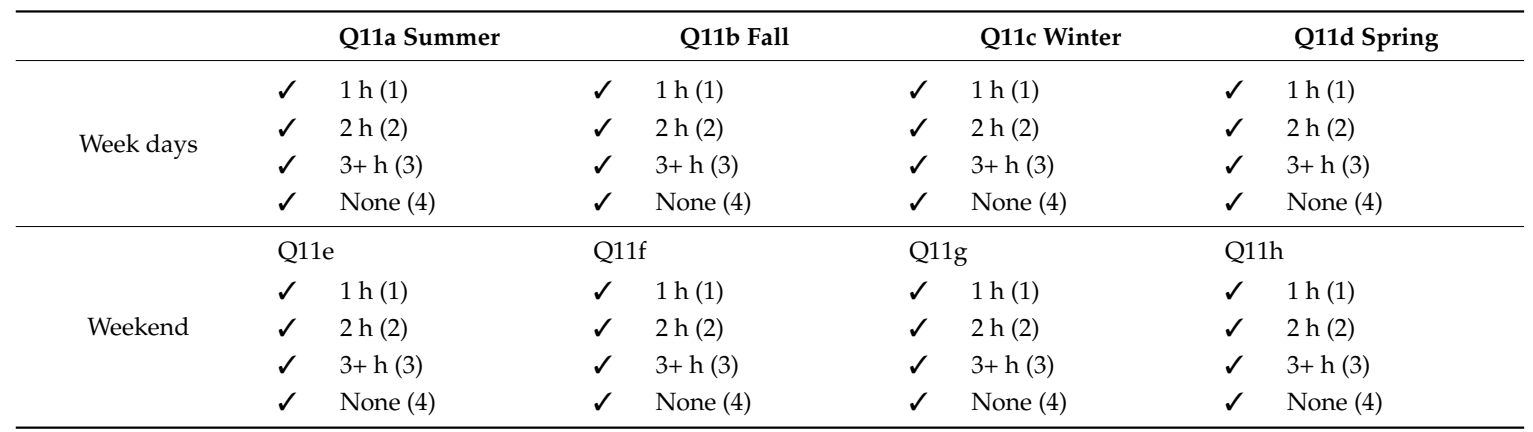

Q12-What kind of transportation do you use to reach the park?

- $\quad$ Walking (How many meters does it take to walk) 1

- Driving my own car 2

- Carpooling (sharing a car with friends) 3

- Public transportation 4

- $\quad$ Biking 5

Q13-For what purposes do you use the park? Please check most preferable option.

- To accompany my child/children 1

- $\quad$ To take a rest 2

- To walk my pet 3

- To have fresh air 4

- $\quad$ To research and observe 5

- To have a picnic 6

- $\quad$ To exercise (running, walking...) 7

\section{Appendix B. Environmental Knowledge. Please Check or Circle the Correct Answer}

Q14-How often do you engage in the following behaviors in your daily life?

a: Going shopping with a reusable shopping bag and refusing plastic/paper bags

- $\quad$ Never (1)

- Sometimes (2)

- Always (3) 
b: Avoiding the purchase of disposable goods

- $\quad$ Never (1)

- $\quad$ Sometimes (2)

- Always (3)

c: Reducing waste as much as possible

- $\quad$ Never (1)

- $\quad$ Sometimes (2)

- $\quad$ Always (3)

d: Taking out old newspapers and empty bottles and cans for recycling or reusable waste collection

- $\quad$ Never (1)

- Sometimes (2)

- Always (3)

e: Taking out unnecessary articles for recycling

- $\quad$ Never (1)

- Sometimes (2)

- Always (3)

f: Not washing oil or other water pollutants down the drain

- $\quad$ Never (1)

- Sometimes (2)

- $\quad$ Always (3)

g: Turning off electric appliances and gas (water?) when not used

- $\quad$ Never (1)

- Sometimes (2)

- Always (3)

h: Using energy: saving electric appliances

- $\quad$ Never (1)

- Sometimes (2)

- $\quad$ Always (3)

i: Using a solar energy water heater or solar panel

- $\quad$ Never (1)

- Sometimes (2)

- Always (3)

$\mathrm{j}$ : Minimizing detergent use

- Never (1)

- Sometimes (2)

- Always (3) 
Q15: Do you know about the concept of a carbon foot print?

- $\quad$ Yes (2)

- $\quad$ No $(1)$

Q16: Do you know the expansion of CFC? If yes, please explain what you know about it

- $\quad$ Yes (2)

- $\quad$ No (1)

Q17: What do you use generally for your daily transportation?

- $\quad$ Walking (1)

- $\quad$ Riding my bike or biking (2)

- Public transportation (3)

- My own car (4)

- Carpooling (5)

Q18: Do you pay more for energy-saving electric appliances

- $\quad$ Yes (2)

- $\quad$ No $(1)$

Q19: Have you heard about the "carbon sequestration" concept?

- $\quad$ Yes (2)

- $\quad$ No (1)

Q20: Have you heard about the "carbon emission" concept?

- $\quad$ Yes (2)

- $\quad$ No (1)

Q21: Do you do sort waste in your house, recycle or compost?

- $\quad$ Yes (2)

- $\quad$ No (1)

Q22: In your opinion, which one is the prior source of global warming?

- Carbon emission (1)

- Greenhouse gasses (2)

- Ozone layer depletion (3)

- CFC (4)

- Water, air, and soil pollutants (5)

Q23: What do you think is most necessary to solve environmental problems?

- Creation and improvement of laws (1)

- Corporate reform and effort (2)

- Technological development (3)

- Education concerning environmental issues (4)

- Better system of collaboration with local people (5)

- Effort of individuals (6)

- $\quad$ No answer (7) 
Q24: Think about things you might do to protect the environment. How often do you do the following?

\begin{tabular}{|c|c|c|c|c|c|c|}
\hline & & Never & Sometimes & Often & Always & Don't Know \\
\hline a & $\begin{array}{l}\text { Decide to re-use something yourself instead of } \\
\text { throwing it for environmental reasons }\end{array}$ & 0 & 1 & 2 & 3 & 4 \\
\hline $\mathrm{b}$ & Compost your food and/or garden wastes & 0 & 1 & 2 & 3 & 4 \\
\hline c & $\begin{array}{l}\text { Recycle bottles/cans / paper/plastic instead } \\
\text { of throwing them away }\end{array}$ & 0 & 1 & 2 & 3 & 4 \\
\hline d & $\begin{array}{l}\text { Buy household products that you think are } \\
\text { better for the environment }\end{array}$ & 0 & 1 & 2 & 3 & 4 \\
\hline e & Get the car tuned regularly & 0 & 1 & 2 & 3 & 4 \\
\hline $\mathrm{f}$ & Make an effort to reduce water consumption & 0 & 1 & 2 & 3 & 4 \\
\hline $\mathrm{g}$ & $\begin{array}{l}\text { Use public transportation, walk or ride to } \\
\text { reduce car use }\end{array}$ & 0 & 1 & 2 & 3 & 4 \\
\hline $\mathrm{h}$ & $\begin{array}{l}\text { Put things in to the gutters or storm water } \\
\text { drains, like oil or detergent }\end{array}$ & 0 & 1 & 2 & 3 & 4 \\
\hline
\end{tabular}

Q25: Could you please CIRCLE your age group?

- $\quad 18-20(1)$

- $\quad 21-29(2)$

- $\quad 30-39(3)$

- $40-49(4)$

- $50-59(5)$

- 60 and over (6)

Q26: Could you please CIRCLE your highest level of education?

- Primary school (1)

- Secondary school (2)

- High school (3)

- College-2 years degree (4)

- College-4 years degree (5)

- College-Master degree or higher (6)

Q27-Please CIRCLE your gender:

- $\quad$ Male (1)

- $\quad$ Female (2)

\section{References}

1. Lafortezza, R.; Sanesi, G.; Chen, J. Large-scale effects of forest management in Mediterranean landscapes of Europe. IFor. Biogeosci. For. 2013, 6, 596-607. [CrossRef]

2. Chen, J.; Liu, Y. Coupled natural and human systems: A landscape ecology perspective. Landsc. Ecol. 2014, 29, 1641-1644. [CrossRef]

3. Chen, J.; Zhu, L.; Fan, P.; Tian, L.; Lafortezza, R. Do green spaces affect the spatiotemporal changes of PM2.5 in Nanjing? Ecol. Process. 2016, 5, 7. [CrossRef] [PubMed]

4. Lafortezza, R.; Chen, J.; van den Bosch, C.K.; Randrup, T.B. Nature-based solutions for resilient landscapes and cities. Environ. Res. 2017. [CrossRef] [PubMed]

5. United Nations. World Urbanization Prospects: The 2014 Revision, Highlights; Department of Economic and Social Affairs, Population Division, United Nations: New York, NY, USA, 2014. 
6. Carrus, G.; Scopelliti, M.; Panno, A.; Lafortezza, R.; Colangelo, G.; Pirchio, S.; Ferrini, F.; Salbitano, F.; Agrimi, M.; Portoghesi, L.; et al. A different way to stay in touch with 'urban nature': The perceived restorative qualities of Botanical Gardens. Front. Psychol. 2017, 8, 914. [CrossRef] [PubMed]

7. Pearlmutter, D.; Calfapietra, C.; Samson, R.; O’Brien, L.; Ostoić, S.K.; Sanesi, G.; del Amo, R.A. The Urban Forest: Cultivating Green Infrastructure for People and the Environment; Springer: Basel, Switzerland, 2017; ISBN 978-3-319-50280-9.

8. Koger, S.M.; Winter, D.D. The Psychology of Environmental Problems: Psychology for Sustainability, 3rd ed.; Lawrence Erlbaum: Mahwah, NJ, USA, 2004; ISBN 978-1-136-94504-5.

9. Gardner, G.T.; Stern, P.C. Environmental Problems and Human Behavior; Pearson Custom Pub.: Upper Saddle River, NJ, USA, 2002; ISBN 978-0-536-68633-6.

10. Vlek, C.; Steg, L. Human behavior and environmental sustainability: Problems, driving forces, and research topics. J. Soc. Issues 2007, 63, 1-19. [CrossRef]

11. Sanesi, G.; Colangelo, G.; Lafortezza, R.; Calvo, E.; Davies, C. Urban green infrastructure and urban forests: A case study of the Metropolitan Area of Milan. Landsc. Res. 2017, 42, 164-175. [CrossRef]

12. Steg, L.; Vlek, C. Encouraging pro-environmental behaviour: An integrative review and research agenda. J. Environ. Psychol. 2009, 29, 309-317. [CrossRef]

13. Crone, J.A. How Can We Solve Our Social Problems? 2nd ed.; SAGE Publications, Inc.: Los Angeles, CA, USA, 2011; ISBN 978-1-4129-7810-1.

14. Hungerford, H.R.; Volk, T.L. Changing learner behavior through environmental education. J. Environ. Educ. 1990, 21, 8-21. [CrossRef]

15. Dwyer, W.O.; Leeming, F.C.; Cobern, M.K.; Porter, B.E.; Jackson, J.M. Critical review of behavioral interventions to preserve the environment: Research since 1980. Environ. Behav. 1993, 25, 275-321. [CrossRef]

16. Brossard, D.; Lewenstein, B.; Bonney, R. Scientific knowledge and attitude change: The impact of a citizen science project. Int. J. Sci. Educ. 2005, 27, 1099-1121. [CrossRef]

17. Zheng, B.; Zhang, Y.; Chen, J. Preference to home landscape: Wildness or neatness? Landsc. Urban Plan. 2011, 99, 1-8. [CrossRef]

18. Hovardas, T.; Korfiatis, K. Effects of an environmental education course on consensus estimates for proenvironmental intentions. Environ. Behav. 2012, 44, 760-784. [CrossRef]

19. Osbaldiston, R.; Schott, J.P. Environmental sustainability and behavioral science: Meta-analysis of proenvironmental behavior experiments. Environ. Behav. 2012, 44, 257-299. [CrossRef]

20. Lafortezza, R.; Carrus, G.; Sanesi, G.; Davies, C. Benefits and well-being perceived by people visiting green spaces in periods of heat stress. Urban For. Urban Green. 2009, 8, 97-108. [CrossRef]

21. Carrus, G.; Lafortezza, R.; Colangelo, G.; Dentamaro, I.; Scopelliti, M.; Sanesi, G. Relations between naturalness and perceived restorativeness of different urban green spaces. Psyecology 2013, 4, 227-244. [CrossRef]

22. Carrus, G.; Scopelliti, M.; Lafortezza, R.; Colangelo, G.; Ferrini, F.; Salbitano, F.; Agrimi, M.; Portoghesi, L.; Semenzato, P.; Sanesi, G. Go greener, feel better? The positive effects of biodiversity on the well-being of individuals visiting urban and peri-urban green areas. Landsc. Urban Plan. 2015, 134, 221-228. [CrossRef]

23. Fishbein, M.; Ajzen, I. Belief, Attitude, Intention and Behavior: An Introduction to Theory and Research; Addison-Wesley: Reading, MA, USA, 1975; ISBN 978-0-201-02089-2.

24. Bargh, J.A.; Morsella, E. Unconscious behavioral guidance systems. In Then a Miracle Occurs: Focusing on Behavior in Social Psychological Theory and Research; Agnew, C.R., Carlston, D.E., Graziano, W.G., Kelly, J.R., Eds.; Oxford University Press: Oxford, UK, 2009; pp. 89-118. ISBN 978-0-19-537779-8.

25. Kollmuss, A.; Agyeman, J. Mind the gap: Why do people act environmentally and what are the barriers to pro-environmental behavior? Environ. Educ. Res. 2002, 8, 239-260. [CrossRef]

26. Cottrell, S.P. Influence of sociodemographics and environmental attitudes on general responsible environmental behavior among recreational boaters. Environ. Behav. 2003, 35, 347-375. [CrossRef]

27. Littledyke, M. Science education for environmental awareness: Approaches to integrating cognitive and affective domains. Environ. Educ. Res. 2008, 14, 1-17. [CrossRef]

28. Richards, R. A new aesthetic for environmental awareness: Chaos theory, the beauty of nature, and our broader humanistic identity. J. Humanist. Psychol. 2001, 41, 59-95. [CrossRef]

29. Wu, S.R.; Greaves, M.; Chen, J.; Grady, S.C. Green buildings need green occupants: A research framework through the lens of the Theory of Planned Behaviour. Arch. Sci. Rev. 2017, 60, 5-14. [CrossRef] 
30. Fan, Y.; Chen, J.; Shirkey, G.; John, R.; Wu, S.R.; Park, H.; Shao, C. Applications of structural equation modeling (SEM) in ecological studies: An updated review. Ecol. Process. 2016, 5, 19. [CrossRef]

31. Hair, J.F., Jr.; Sarstedt, M.; Hopkins, L.; Kuppelwieser, V.G. Partial least squares structural equation modeling (PLS-SEM): An emerging tool in business research. Eur. Bus. Rev. 2014, 26, 106-121. [CrossRef]

32. Hair, J.F., Jr.; Hult, G.T.M.; Ringle, C.M.; Sarstedt, M. A Primer on Partial Least Squares Structural Equation Modeling, 1st ed.; SAGE Publications, Inc.: Los Angeles, CA, USA, 2013; ISBN 978-1-4833-7746-9.

33. Efron, B.; Tibshirani, R. Bootstrap methods for standard errors, confidence intervals, and other measures of statistical accuracy. Stat. Sci. 1986, 1, 54-75. [CrossRef]

34. Davison, A.C.; Hinkley, D.V. Bootstrap Methods and Their Application, 1st ed.; Cambridge University Press: Cambridge, UK; New York, NY, USA, 1997; ISBN 978-0-521-57471-6.

35. Shteir, A.B. Gender and "modern" botany in Victorian England. Osiris 1997, 12, 29-38. [CrossRef] [PubMed]

36. Parry, D.C.; Glover, T.D.; Shinew, K.J. ‘Mary, mary quite contrary, how does your garden grow?: Examining gender roles and relations in community gardens. Leis. Stud. 2005, 24, 177-192. [CrossRef]

37. Harland, P.; Staats, H.; Wilke, H.A.M. Explaining proenvironmental intention and behavior by personal norms and the theory of planned behavior. J. Appl. Soc. Psychol. 1999, 29, 2505-2528. [CrossRef]

38. Haas, M.R.; Hansen, M.T. Different knowledge, different benefits: Toward a productivity perspective on knowledge sharing in organizations. Strateg. Manag. J. 2007, 28, 1133-1153. [CrossRef]

39. Han, H.; Hsu, L.-T.; Sheu, C. Application of the theory of planned behavior to green hotel choice: Testing the effect of environmental friendly activities. Tour. Manag. 2010, 31, 325-334. [CrossRef]

40. Gregory, G.D.; Leo, M.D. Repeated behavior and environmental psychology: The role of personal involvement and habit formation in explaining water consumption. J. Appl. Soc. Psychol. 2003, 33, 1261-1296. [CrossRef]

41. Baumeister, R.F.; Vohs, K.D.; Funder, D.C. Psychology as the science of self-reports and finger movements: Whatever happened to actual behavior? Perspect. Psychol. Sci. 2007, 2, 396-403. [CrossRef] [PubMed]

42. Arcury, T.A.; Johnson, T.P.; Scollay, S.J. Ecological worldview and environmental knowledge: The "new environmental paradigm". J. Environ. Educ. 1986, 17, 35-40. [CrossRef]

43. Fan, P.; Wan, G.; Xu, L.; Park, H.; Xie, Y.; Liu, Y.; Yue, W.; Chen, J. Walkability in urban landscapes: A comparative study of four large cities in China. Landsc. Ecol. 2018, 33, 323-340. [CrossRef]

44. Dresner, M.; Handelman, C.; Braun, S.; Rollwagen-Bollens, G. Environmental identity, pro-environmental behaviors, and civic engagement of volunteer stewards in Portland area parks. Environ. Educ. Res. 2015, 21, 991-1010. [CrossRef] 